\section{Postgraduate specialisation}

The College of Medicine at the University of Malawi has offered postgraduate training only since 2005 in certain specialties, in conjunction with certain universities in South Africa. This does not include psychiatry, so all psychiatric training at present has to be done outside Malawi.

\section{Psychiatric nurses}

The St John of God College of Health Sciences provides a degree in psychiatric nursing for registered state nurses with a minimum of a university diploma in nursing, and the Malawi College of Health Sciences provides a certificate course in psychiatry for enrolled nurses.

\section{Research}

Mental health in Malawi has been the subject of several research projects. These have included studies in psychoactive substances, the teaching of psychiatry in the colleges and attributions for admissions to Zomba Mental Hospital (MacLachlan et al, 1995). More studies are under way or being developed by Zomba Mental Hospital on, for example:

O community attitudes to and knowledge of mental illness

$O$ the prevalence of HIV and neurosyphilis among inpatients

O district mental health activities in southern Malawi, including what proportions of the district budgets are allocated to mental health

O common causes of relapse and readmission in patients with schizophrenia

O pathways to care for psychiatric patients

O neuropsychological sequalae of cerebral malaria.

At the St John of God Hospital a randomised controlled trial of carer education in schizophrenia and bipolar disorders is under way.

In general, there is not much information on mental health in the Malawian context and this provides opportunities and challenges for research.

\section{Professional organisations}

In the past there was a Mental Health Association of Malawi, but it stopped functioning, for unknown reasons, around 1999. At present, a 'core group' is being formed, comprising: the psychiatrist at Zomba Mental Hospital; the clinical psychologist at the Malawi College of Medicine; the chief nursing officer at Zomba Mental Hospital; and the psychiatric clinical officer at the St John of God Hospital. The main goal of this core group is to develop the preliminary constitution of a new professional association and to recruit members. Some of the functions of the association will be:

$O$ to deal with challenges in mental health

O to act as an advisory body to the Medical Council of

Malawi on the registration of mental health professionals

O to develop, review and conduct policy for mental health professionals.

There are at present no non-governmental organisations operating in the mental health field in Malawi.

\section{Challenges}

Notable problems include a critical shortage of trained staff and frequent shortages of drugs owing to procurement problems. The referral system is not very good; neither is follow-up care, as most district psychiatric services seem to be insufficiently well developed.

\section{References}

MacLachlan, M., Nyirenda, T. \& Nyando C. (1995) Attributions for admission to Zomba Mental Hospital: implications for the development of mental health services in Malawi. International Journal of Psychiatry, 41, 79-87.

National Statistical Office of Malawi. See http://www.nso.malawi.net/ data_on_line/demography/census_98/mortality_measures.htm. Last accessed 23 October 2006.

World Health Organization (2005) Mental Health Atlas 2005. See http:// www.who.int/globalatlas/predefinedReports/MentalHealth/Files/MW Mental_Health_Profile.pdf. Last accessed 23 October 2006.

\title{
Mental health and psychiatry in Thailand
}

\section{Pichet Udomratn MD}

Department of Psychiatry, Faculty of Medicine, Prince of Songkla University, Hat Yai, Songkhla, 90110, Thailand, email upichet@medicine.psu.ac.th

\footnotetext{
hailand is located in Southeast Asia and covers an area of $513115 \mathrm{~km}^{2}$. In 2006 its population was approximately 64 million. The major nationality is Thai. About $80 \%$ of the total population live in rural areas. The country is composed of 76 provinces, divided into a total of 94 districts and 7159 sub-districts.
}

\section{Prevalence of mental illnesses}

The latest data concerning the prevalence of mental disorders in Thailand were obtained from a national survey conducted in 2003. The survey was a two-step cross-sectional community survey using AUDIT (Alcohol Use Disorders 
Identification Test) and MINI (Mini-International Neuropsychiatric Interview). There were 11700 participants, aged 15-59 years, selected by stratified two-stage cluster sampling. The top three problems found (1-month prevalence) were alcohol use disorders (28.5\%), major depressive disorder (3.2\%) and generalised anxiety disorder (1.9\%) (Siriwanarangsan et al, 2004).

\section{Mental health policy and legislation}

The current mental health policy was formulated in 1995. Its main components are advocacy, promotion, treatment and rehabilitation, but it also includes sections on administration and technical development. The policy plan is to promote mental health and prevent mental health problems, to expand and develop treatment and rehabilitation services, to develop a management system to reform all aspects of mental health services, and to develop modern psychosocial and other technical knowledge in order to apply them fruitfully to Thailand's mental health situation (World Health Organization, 2001).

There is at present no mental health legislation, although a Mental Health Bill, which was drafted by the Department of Mental Health and then revised according to suggestions from service providers, carers and ex-patients during a public hearing process, has been submitted to parliament. However, parliament was dissolved in February 2006 following an army coup and we must now wait until we get a new parliament to approve the Bill. The Mental Health Bill is, in essence, similar to the legislation enacted in other countries, in that all persons in need of psychiatric treatment either will be able to access it voluntarily or will be compulsorily brought to a hospital for evaluation and to receive treatment.

\section{The healthcare system}

The system was originally set up (before 2001) so that those with a medical problem were expected to consult first in the primary care setting; then, if necessary, they would be referred to secondary and if necessary tertiary care. (These services are described below.) However, in reality, patients could go directly to any level they chose. Many were first seen at secondary or tertiary settings, including university hospitals. Except for those with a psychosis, referral of patients from primary to secondary care seldom happened - patients were referred directly to a tertiary service or a psychiatric hospital.

Since the last government introduced the policy of universal coverage under its '30 baht healthcare scheme' in 2001 (30 baht is approximately 0.60 euros), referral systems have been strengthened. Under this scheme, people who have no health insurance must register with a nearby hospital. If they are ill, they can go to that hospital and pay the hospital only 30 baht per visit. This covers all kinds of treatment, from medication to open-heart surgery. If doctors at the registered hospital cannot treat that patient for any reason, they will refer the patient to a larger hospital, which will in turn send the bill for reimbursement back to the first hospital.
The government allocates a yearly budget to each hospital according to its number of registered patients. The hospitals received 1202 baht per registered patient per year in 2003, which increased to 1308 baht in 2004, 1396 baht in 2005 and to 1659 baht for 2006. This budget is meant to cover all expenses, including salaries, equipment and materials. Under this scheme, patients now are unable to visit a doctor in a secondary or tertiary care setting without a referral letter from the registered hospital, unless they are prepared to pay all of the expenses out of their own pocket (Udomratn, 2006). In October 2006, the new interim government scrapped payment of 30 baht per visit but the system remains the same.

\section{Primary care services}

These cover all areas of the country and fall under the administration of the Ministry of Public Health, except in Bangkok, which is under the Bangkok Metropolitan Administration. The services located nearest the local communities are the sub-district health centres, each of which is run by three or four health workers. Their main function is the prevention of illness, although they also provide treatment for simple illnesses or problems. If the problem is beyond their ability they refer the patient to the district (community) hospital. There are about 8800 sub-district health centres covering the whole country.

The second level of primary care service is the district hospital, which typically has one or two physicians, between five and seven nurses and 10-30 beds. The largest district hospital has 120 beds. Out-patient services are the main provision. Currently there are approximately 695 district hospitals in Thailand.

\section{Secondary care services}

These are the responsibility of the general hospitals, which typically have 100-120 beds and are located in each of the 76 provinces. A few provinces have two general hospitals. Typically, five specialised services (medicine, paediatrics, surgery, obstetrics and gynaecology, and orthopaedics) are provided by the general hospitals. There may be a psychiatric unit in the general hospital, but this will usually be supervised by a non-psychiatrist physician and a psychiatric nurse: only about a third of the general hospitals have a psychiatrist as the head of the psychiatric unit.

\section{Tertiary care services}

There are about 20 tertiary care hospitals, with 150-200 beds or more, located in the larger provinces. Patients with complications are referred from primary and secondary care. More specialists are available in these hospitals and some have psychiatric staff.

Medical school hospitals also provide tertiary care. There are eight medical schools in seven universities in Thailand. One is under the control of the Ministry of Defence and one is run by a private organisation.

\section{Mental health services}

Before 1964, all mental health activities were located in mental health or psychiatric hospitals. Psychiatrists and their colleagues acted as the sole providers of services. During the First to Third Five-Year National Health Plans (1962-76), 
Table 1 Mental health personnel and proportion to the whole population, by region ${ }^{1}$

\begin{tabular}{|c|c|c|c|c|c|c|c|c|}
\hline \multirow[t]{2}{*}{ Region } & \multicolumn{2}{|c|}{ Psychiatrists } & \multicolumn{2}{|c|}{ Psychiatric nurses } & \multicolumn{2}{|c|}{ Psychologists } & \multicolumn{2}{|c|}{ Social workers } \\
\hline & $n$ & Ratio $^{2}$ & $n$ & Ratio $^{2}$ & $n$ & Ratio $^{2}$ & $n$ & Ratio $^{2}$ \\
\hline Bangkok & 218 & $1: 26267$ & 173 & 1:33099 & 42 & $1: 136338$ & 117 & 1:48942 \\
\hline Central & 75 & $1: 195374$ & 481 & $1: 30464$ & 44 & $1: 333023$ & 78 & $1: 187859$ \\
\hline North & 31 & 1:391111 & 308 & 1:39365 & 45 & 1:269432 & 84 & 1:144338 \\
\hline North-East & 39 & 1:551 120 & 551 & $1: 39009$ & 48 & $1: 447785$ & 61 & $1: 352356$ \\
\hline South & 24 & $1: 346315$ & 222 & $1: 37439$ & 17 & $1: 488916$ & 33 & $1: 251866$ \\
\hline Total & 387 & 1:161005 & 1735 & 1:35913 & 196 & 1:317902 & 373 & 1:167048 \\
\hline
\end{tabular}

1. Data from the Department of Mental Health, Ministry of Public Health, 2003.

2. Ratio: ratio of staff to regional/national population.

mental health activities were extended to community health services.

Nowadays psychiatric care is provided in the government, private and non-governmental sectors. The public sector, mainly supported by the government budget, includes the Ministry of Public Health, the Ministry of Education, the Interior Ministry, the Ministry of Defence and the Office of the National Police. The Ministry of Public Health includes the Department of Mental Health, the Office of the Permanent Secretary and the Medical Department, which oversees many psychiatric units and psychiatrists.

All government hospitals face the problems of too many patients, lack of staff and under-financing. Most hospitals have additional income from fees and donations, but even so their total expenses are almost always higher than their total income.

At the moment there are about 400 psychiatrists working in Thailand. Most are public sector employees who also have a private practice outside their official hours. Not only is the number of psychiatrists insufficient but there is also a lack of other mental health personnel (Table 1), especially occupational therapists, of whom there are only 49 nationally (ratio $1: 1271610$ ). Moreover, the distribution is also skewed, with more than half the total number of psychiatrists working in Bangkok (Table 1) and most of the rest working in the other big cities.

Most specialised care is offered by the psychiatric hospitals. In 2001, there were nine of these, with a total capacity of 8893 beds (Boonyawongvirot, 2003). They provide inpatient services, out-patient clinics, emergency services, rehabilitation services, education and training, and mental health promotion and prevention services. There are also two mental health centres, which provide out-patient services and which emphasise mental health promotion and prevention. There are also two sub-specialty psychiatric hospitals, the Forensic Psychiatric Hospital and the Institute of Mental Health for Children and Family.

\section{Problems of the mental healthcare system}

The main problems to be found in the mental healthcare system in Thailand can be summarised as follows:

O The number of mental health workers is insufficient (see Table 1).

O General physicians and general practitioners are not confident in the assessment and management of psychiatric patients. Some psychiatric disorders, especially depression, are under-diagnosed, whereas other diagnoses are made too often, such as anxiety disorders. Many patients receive anxiolytic or antidepressant medication in sub-therapeutic doses. (Patients with a psychosis are an exception, as most are directly referred to psychiatric hospital.)

o The primary and secondary care services have little opportunity to care for psychiatric patients during the continuation and maintenance phases of their illness because of limited supplies of medications. District hospitals usually have only haloperidol for schizophrenia and amitriptyline or imipramine for depression. Although the Ministry of Public Health added fluoxetine (generic) to the list of essential hospital drugs a few years ago, only the central hospital and a few general hospitals are able to supply this. Atypical antipsychotics have only just been supplied to psychiatric hospitals, university hospitals and some central hospitals, but they are not covered by health insurance unless the medical committee of the hospital decides, on a case-by-case basis, that they are necessary. The shortage of psychiatric drugs at local hospitals, the long distances that patients have to travel to get treatment, and the high cost of travel (because of increasing fuel prices) are also problems for continuation of treatment.

O Patients and their families have a poor understanding of psychiatric disorders. In the case of psychoses, most have some knowledge about the symptoms but tend to believe that they were caused by stress, worry or supernatural influences. This may result in patients discontinuing their treatment early.

O During the continuation and maintenance phases of treatment, even though some mental health teams in general hospitals can monitor symptoms, adjust the doses of drugs and provide psychosocial intervention, often the patients and their families still prefer to see a psychiatrist, and this overloads many psychiatrists in tertiary care.

\section{Role of carers}

In January 1995, the PRELAPSE (Preventing Relapse in Schizophrenia) programme was introduced in Thailand. This was implemented in five psychiatric hospitals under the Department of Mental Health. Preliminary results showed that for patients with schizophrenia whose families joined this programme, the readmission rate decreased by $44 \%$ and the length of hospital stay decreased for $50 \%$ of patients (Udomratn, 1999). After evaluating these preliminary results, the Department transformed this programme into the 'Technology for Caring Relatives of Schizophrenic Patients' programme and some hospitals integrated it into their routine services. Many relatives who joined in the educational activities later agreed to meet regularly and formed clubs at various psychiatric hospitals 
throughout the country. These clubs went on to form the Association for the Mentally III (AMI), in 2003. The AMI now receives funding from the Thai Health Promotion Foundation, the Health Systems Research Institute of Thailand and other agencies. The AMI has contributed to many activities related to mental health promotion and prevention, and to increasing awareness of mental health problems in Thailand.

\section{Conclusions}

Psychiatric services in Thailand, as in many low- and middleincome countries, still face shortages of mental health workers. Mental health problems are not well recognised by general practitioners. Patients' poor understanding of psychiatric disorders causes a delay in seeking help and frequently early discontinuation of drug treatment.

Many strategic plans have been initiated by the Thai Department of Mental Health, with the aim of increasing human resources and providing a better quality of care in both general and psychiatric hospitals. Destigmatisation campaigns have been run. We expect a brighter future for Thai psychiatric patients and their families within the next decade.

\section{References}

Boonyawongvirot, P. (ed.) (2003) Mental Health in Thailand, 2002-2003. ETO Press.

Siriwanarangsan, P., Kongsuk, T., Arunpongpaisan, S., et al (2004) Prevalence of mental disorders in Thailand: a national survey, 2003. Journal of Mental Health of Thailand, 12, 177-188.

Udomratn, P. (1999) The progress of the PRELAPSE program in Thailand. Journal of the Psychiatric Association of Thailand, 44, 171-179.

Udomratn, P. (2006) Psychiatry in Thailand. In Textbook of Psychiatry in Asia (eds E. Chiu, H. Chiu, E. H. Kua, et al). Peking University Medical Press.

World Health Organization (2001) Atlas: Country Profiles 2001. Available at http://w3.whosea.org/LinkFiles/Health_and_Behaviour_tha.pdf. Last accessed 23 October 2006.

\section{Lebanon}

\section{F. Antun ${ }^{1}$ MD PhD FRCP FRCPsych DPM, Charles Baddoura ${ }^{2}$ and Mounir Khani ${ }^{3}$ MD}

1Professor of Psychiatry, Adviser and WHO National Focal Point for Mental Health, Ministry of Health, Beirut, Lebanon, email antun@cyberia.net.lb

${ }^{2}$ Professor of Psychiatry, Saint Joseph University, Beirut, Hospital of the Cross, Lebanon

${ }^{3}$ American Board of Psychiatry and Neurology, Clinical Associate Professor of Psychiatry, American University of Beirut Medical Center, Beirut, Lebanon

ebanon is a western Asian country with an area of $10452 \mathrm{~km}^{2}$ and a population of around 4 million (excluding the 10 million Lebanese immigrants worldwide). It has approximately 60 psychiatrists, mostly concentrated in the capital, Beirut, although a trend for decentralisation is currently observed. The number of psychiatrists is steadily increasing as postgraduate training centres have been established during the past decade. There are, however, few sub-specialists, owing to a lack of adequate training programmes.

\section{Training}

\section{Undergraduate training}

Six schools of medicine offer medical undergraduate education. The 7-year curriculum includes courses on psychology, psychopathology, psychotherapies and general psychiatry. A typical example would be the undergraduate training programme at the American University of Beirut Medical School, where the Department of Psychiatry offers an undergraduate course to 'Med II' students and a clinical clerkship to 'Med III' students, as well as clinical electives to interns and residents. It also provides training and supervision for psychologists. The course covers:

O Psychopathology. A DSM-IV-based course introduces Med II students to normal and abnormal psychological mechanisms as well as the classification and pathophysiology of psychiatric illnesses.

o Clinical clerkship in psychiatry. Third-year medical students spend 1 month working on psychiatric cases and attending morning rounds on a psychiatric service. They are supervised by an attending psychiatrist. Students also attend the psychiatry clinic in the out-patient department, where they see new cases and prepare seminars.

The rotation also includes seminars on psychopathology, case presentation and discussions, interview techniques and basic psychotherapy, as well as psychopharmacology. Seminars are held daily and are supervised by the faculty members.

\section{Postgraduate training}

Psychiatrists go through a 4-year postgraduate training programme provided by two universities. This includes a 1 -year rotation on medical wards (with a specific focus on neurology) as well as exposure to child, adult and geriatric psychiatry through in-patient psychiatric wards and out-patient facilities. One of these universities (Saint Joseph University, which, since the 1980s, has been affiliated to the Saint Anne Psychiatric University Centre in Paris, France) requires six research subjects, a university diploma in cognitive-behavioural therapy (CBT) and passing a neuropsychiatry examination in order to grant the specialty certificate; the other requires passing the Arab Board of Psychiatry examination (in its three parts). 